\title{
Study on Characteristics and Microstructure of Ni-AIN Thin Coatings Prepared via Different Electrodeposition Techniques
}

\author{
Zhongguo Yang ${ }^{1}$, Shujuan $\mathrm{Yi}^{2, *}$, Yun Wang ${ }^{1}$, Shengxue Zhao ${ }^{2}$, Wang Shi ${ }^{2}$ \\ ${ }^{1}$ College of Civil Engineering and Water Conservancy, Heilongjiang Bayi Agricultural University, \\ Daqing 163319, China; \\ ${ }^{2}$ College of Engineering, Heilongjiang Bayi Agricultural University, Daqing 163319, China \\ *E-mail: gyang109@163.com
}

Received: 11 October 2021 / Accepted: 3 December 2021 / Published: 5 January 2022

\begin{abstract}
In this work, pulse-current (PC), direct-current (DC), and deposition of ultrasonic-assisted pulse-current (UAPC) were used to produce Ni-AlN thin coatings. X-ray diffractometer (XRD), scanning electron microscopy (SEM), scanning probe microscopy (SPM), Vickers hardness assessment, as well as electrochemical station were used to examine the microhardness, microstructure, and erosion properties of Ni-AlN thin coatings. The coatings based on Ni-AlN, generated using UAPC deposition had a fine compact morphological property. The respective mean grain sizes of the particles of $\mathrm{Ni}$ and AlN were about 97.4 and $40.1 \mathrm{~nm}$, according to the SPM data. The thin coatings comprise Ni and AlN phases, according to the XRD data. The thin coatings of Ni-AlN produced using PC, DC and UAPC deposition techniques, respectively, demonstrated optimum microhardness values of 939, 902, and $986 \mathrm{HV}$ when the current density was $4.5 \mathrm{~A} / \mathrm{dm} 2$. When compared to the corrosion resistance of the coatings obtained through UAPC deposition with the other two types of thin coatings, the results showed that the coatings obtained through UAPC deposition manifested the highest value of corrosion resistance.
\end{abstract}

Keywords: Electrodeposition; microstructure; Ni-AlN thin coating; corrosion

\section{$\underline{\text { FULL TEXT }}$}

(C) 2022 The Authors. Published by ESG (www.electrochemsci.org). This article is an open access article distributed under the terms and conditions of the Creative Commons Attribution license (http://creativecommons.org/licenses/by/4.0/). 